\title{
APROPRIAÇÃO DO DISCURSO DE INOVAÇÃO CURRICULAR EM QUÍMICA POR PROFESSORES DO ENSINO MÉDIO: PERSPECTIVAS E TENSÕES
}

\author{
Appropriation of a Chemistry curricular innovation \\ discourse for secondary school teachers: \\ perspectives and tensions
}

\author{
Murilo Cruz Leal ${ }^{1}$ \\ Eduardo Fleury Mortimer ${ }^{2}$
}

\begin{abstract}
Resumo: O objetivo deste trabalho é analisar como professores do Ensino Médio se apropriam de um discurso de inovação curricular de Química. O estudo baseia-se em entrevistas realizadas com 12 professores participantes do PRÓ-MÉDIO e do PRÓ-CIÊNCIAS, programas de formação continuada e inovação curricular ocorridos em Minas Gerais de 1997 a 1999. A análise do discurso dos professores baseia-se na "metalingüística" de Mikhail Bakhtin, utilizando sobretudo os conceitos de apropriação do discurso do outro e polifonia. Assim, pudemos ouvir as diversas vozes que se fazem presentes no discurso de cada professor, num processo complexo de justificação, acordo, competição e dissimulação, dentre outras dinâmicas, criando e recriando sentidos de inovação. A experiência do professor ora é aliada da cultura escolar, na crítica aos discursos idealizados da academia, ora se contrapõe a certas práticas escolares tradicionais já desgastadas e faz-se aliada da inovação.
\end{abstract}

Palavras-chave: Ensino de Química. Inovação curricular. Professores. Discursos.

\begin{abstract}
The aim of this investigation is to analyze how secondary school teachers appropriate the discourse of chemistry curriculum innovation. The study is based on interviews carried out with 12 teachers who have taken part in the PRÓ-MÉDIO and PRÓ-CIÊNCIAS programs of continued training and innovation implemented in Minas Gerais State in Brazil, from 1997 to 1999. The appropriation of the innovation discourse by the teachers is dealt with based on the "metalinguistic" perspective of Mikhail Bakhtin, using mainly the concepts of appropriation of the discourse of the other and polyphony. Thus, it was possible to listen to the different voices within the discourse of each teacher, in a complex process of justification, accordance, competition and dissimulation, among other dynamics, creating and re-creating the meanings of innovation. The teacher's experience sometimes acts as an ally to the school culture in the criticism of idealized academic discourses; sometimes it is in opposition to certain traditional teaching practices, becomes an ally of innovation.
\end{abstract}

Keywords: Chemical education. Curricular innovation. Teachers. Discourses.

\footnotetext{
${ }^{1}$ Licenciado em Química, Mestre em Agroquímica, Doutor em Educação. Professor do Departamento de Ciências Naturais da Universidade Federal de São João del-Rei, UFSJ. São João Del-Rei, MG, Brasil.

<mcleal@ufsj.edu.br>

${ }^{2}$ Bacharel e Licenciado em Química, Mestre e Doutor em Educação. Professor da Faculdade de Educação da Universidade Federal de Minas Gerais, UFMG. Belo Horizonte, MG, Brasil. <mortimer@dedalus.lcc.ufmg.br>

${ }^{1}$ Universidade Federal de São João del-Rei

Praça Frei Orlando, 170

São João del-Rei, MG

$36.307-352$ 
Leal, M. C.; Mortimer, E. F.

\title{
Introdução
}

\author{
Quanto mais intensa, diferenciada e elevada for a vida social \\ de uma coletividade falante, tanto mais a palavra do outro, \\ o enunciado do outro, como objeto de uma comunicação interessada, \\ de uma exegese, de uma discussão, de uma apreciação, \\ de uma refutação, de um reforço, de um desenvolvimento posterior etc., \\ tem peso específico maior em todos os objetos do discurso.
} Mikhail Bakhtin (1998, p. 139)

Neste estudo, analisamos a apropriação, pelos professores do Ensino Médio, de uma nova proposta curricular de Química (MINAS GERAIS, 1998a), buscando elucidar alguns aspectos do complexo sistema constituído pela proposição e implantação de uma inovação educacional. Nosso foco de atenção coloca-se sobre os processos de produção e negociação de sentidos que se realizam no interior dos discursos.

Tal estudo foi construído com base em entrevistas realizadas, em 2000 e 2001, com doze professores que participaram dos programas de formação continuada em que a nova proposta foi apresentada. No período de 1997 a 1999, parcelas dos professores mineiros do Ensino Médio participaram do PRÓ-MÉDIO, um programa da Secretaria de Estado da Educação, ou das edições III e IV do PRÓ-CIÊNCIAS, um programa da CAPES, em convênio com as Secretarias de Estado de Ciência e Tecnologia e de Educação de diversos estados da Federação (MINAS GERAIS, 2000a, 1999a, 1999b, 1998b, 1998c, 1997; BRASIL, 1999a, 1995). As edições desses dois programas constituíram-se de três e quatro etapas de quarenta horas cada, respectivamente. Em Minas Gerais, a terceira edição do PRÓ-CIÊNCIAS funcionou como uma etapa de generalização do ideário desenvolvido para o PRÓ-MÉ$\mathrm{DIO}^{3}$. Cerca de duzentos a trezentos professores de Química, de todo o estado, foram atendidos em cada um desses momentos de formação continuada. O grupo entrevistado para este estudo corresponde à totalidade dos professores das escolas sob jurisdição da Superintendência Regional de Ensino de São João Del-Rei que participou dos programas.

Além dos discursos dos professores, interessa-nos considerar o discurso curricular que lhes fora apresentado pela Secretaria de Estado de Educação. Em um esforço de síntese, poderíamos dizer que a nova proposta curricular fundamenta-se em três esquemas de articulação orientados a superar a abordagem linear que caracterizaria o ensino tradicional. Esses três esquemas colocam-se, respectivamente, nos seguintes níveis: da relação da ciência química

\footnotetext{
${ }^{3} \mathrm{Na}$ edição seguinte, já no mandato de outro Governador, o PRÓ-CIÊNCIAS ainda se manteve afinado com os pressupostos do PRÓ-MÉDIO. Na concepção da quinta edição do PRÓ-CIÊNCIAS (MINAS GERAIS, 2000b), entretanto, a SECT/MG e a SEE/MG colocam as Diretrizes Curriculares Nacionais e os Parâmetros Curriculares Nacionais (BRASIL, 1999b e 1999c) como "os documentos que norteiam a reforma" pela qual o Ensino Médio está passando em nosso país (MINAS GERAIS, 2000b, p. 12). Percebe-se, naquele momento, o rompimento com a centralidade dada, nas duas edições anteriores, às propostas e materiais elaborados no PRÓ-MÉDIO.
} 
Apropriação do discurso de inovação curricular ...

com os diferentes aspectos da realidade humana (contextualização da Química); das temáticas próprias da química (conceituação química), e, finalmente, da natureza e do funcionamento dessa ciência (epistemologia). Desse modo, no primeiro nível, temos a articulação entre os conceitos químicos e os contextos social, ambiental e tecnológico; no segundo nível, temos a articulação entre o que os autores denominam "os focos de interesse da Química", as propriedades, a constituição e as transformações de substâncias e materiais; finalmente, em um terceiro nível de articulação, situam-se os aspectos constituintes do conhecimento químico: o fenomenológico, o teórico e o representacional. Os esquemas seguintes (Figura 1), reproduzidos do texto da nova proposta curricular, representam esses dois últimos níveis.

TCOCOSDEINTERESSEDAQUIMICA

[AS INTER-RELAÇÕES ENTRE OS OBJETOS DE INTERESSE DA QUÍMICA]

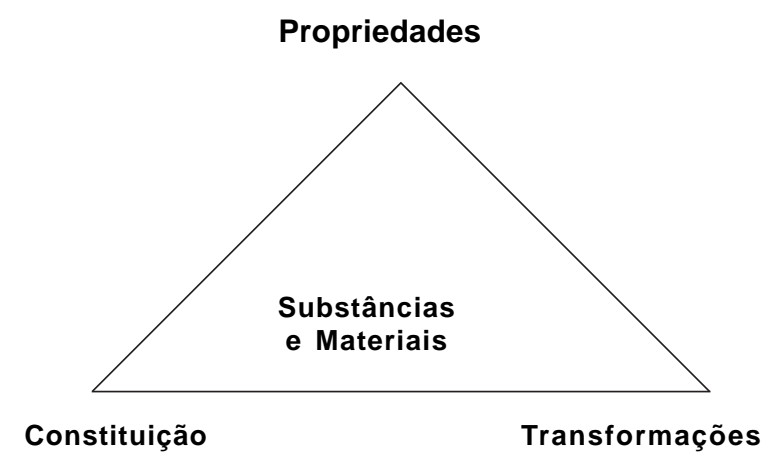

\section{ASPECTOS DO CONHECIMENTO QUÍMICO}

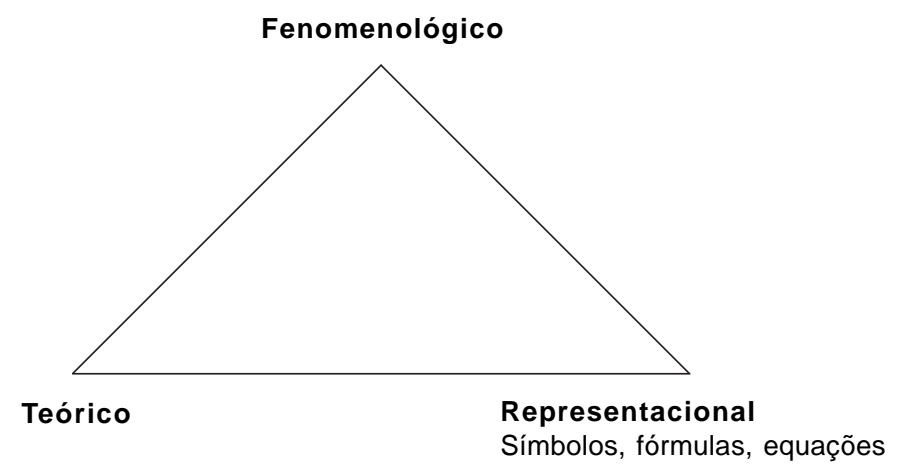

Figura 1. Focos de interesse da Química e aspectos do conhecimento químico (MINAS GERAIS, 1998a). 
Leal, M. C.; Mortimer, E. F.

Como esses fundamentos são apropriados pelos professores do Ensino Médio ou, em outras palavras, como eles são recontextualizados no espaço concreto e ideológico daqueles a quem cabe realizar o ensino de Química no nível médio? Esta é a questão que pretendemos responder, focalizando-nos em perspectivas dominantes e tensões que se atualizam nos discursos dos professores sobre a inovação curricular. Entendemos que as percepções e apreciações dos professores fornecem elementos relevantes para, em uma perspectiva ampla que transcende o objetivo específico desta pesquisa, atingirmos uma compreensão mais clara e profunda da situação atual do ensino de Química em nosso estado e no país, envolvendo aí as práticas, as relações e os discursos constituintes de tal situação. É como se a circunstância de inovação curricular nos fornecesse um "estado excitado do ensino de Química", favorável à coleta de informações sobre a natureza e a dinâmica desse sistema.

\section{Ouvindo vozes com os ouvidos de Mikhail Bakhtin: as interações discrusivas na perspectiva da metalingüística ${ }^{4}$}

O aporte teórico fornecido por Mikhail Bakhtin, centrado na questão da enunciação, constitui o espaço teórico-metodológico para, com base nas entrevistas, construirmos significações e ampliarmos nossa compreensão das percepções e apreciações construídas pelos professores de Química do Ensino Médio tomando por base a proposição de inovação curricular ocorrida recentemente em Minas Gerais.

Para Bakhtin (2000), se, de um lado, temos a oração como unidade da língua, de outro, temos, no enunciado, "a unidade real da comunicação verbal” (p. 292). Independente de conteúdo, extensão ou composição, todo e qualquer enunciado possui três características estruturais comuns: 1) as fronteiras, que são exemplificadas na situação de diálogo entre pessoas, pela alternância dos sujeitos falantes; 2) o acabamento, o todo do enunciado, que resulta da associação de tratamento exaustivo do objeto, intuito discursivo (on o querer dizer do locutor) e escolha de um gênero do discurso; 3) a relação do enunciado com o próprio locutor e com os outros parceiros da comunicação verbal (BAKHTIN, 2000).

\footnotetext{
${ }^{4}$ Bakhtin denomina "metalingüística" a abordagem que desenvolveu para o estudo de textos e discursos, identificados por ele, de forma geral, como enunciados. Mais precisamente, a ênfase de Bakhtin está na enunciação. Todorov fala em "translingüística" e "pragmática" é outro termo usado para identificar o tipo de abordagem desenvolvido por Bakhtin (TODOROV, 2000, p. 15). Relativamente disperso por sua obra, encontramos um Bakhtin preocupado com os temas da linguagem e da produção discursiva em Marxismo $e$ filosofia da linguagem, Problemas da poética de Dostoievski, O discurso no romance (presente na coletânea Questões de literatura e de estética) e nos textos Os gêneros do discurso e O problema do texto, que foram reunidos em Estética da criação verbal. Essa coletânea foi organizada em 1979, após a morte de Bakhtin, em 1975; seus dois textos aqui utilizados foram escritos, respectivamente, em 1952-53 e 1959-60. Para uma apresentação mais extensa e bem situada dessa vertente da obra de Bakhtin, ver Todorov (2000), Barros (1996) e Faraco (1999).
} 
Apropriação do discurso de inovação curricular ...

Os enunciados são, portanto, fruto da articulação de conteúdo, contexto e expressividade: “[...] apenas o contato entre a significação lingüística e a realidade concreta, apenas o contato entre língua e realidade - que se dá no enunciado - provoca o lampejo da expressividade. Esta não está no sistema da língua e tampouco na realidade objetiva que existiria fora de nós" (BAKHTIN, 2000, p. 311).

Em outro texto, Bakhtin indica, de forma sintética, o sentido de enunciado e enunciação em sua obra:

O enunciado existente, surgido de maneira significativa num determinado momento social e histórico, não pode deixar de tocar os milhares de fios dialógicos existentes, tecidos pela consciência ideológica em torno de um dado objeto de enunciação, não pode deixar de ser participante ativo do diálogo social. Ele também surge desse diálogo como seu prolongamento, como sua réplica, e não sabe de que lado ele se aproxima desse objeto. (BAKHTIN, 1993, p. 86)

Além das determinações devidas ao contexto, há o interlocutor (ou destinatário), um outro, também participante do diálogo social, a quem se dirige o discurso e a quem tal discurso também pertence. Discursos são sempre territórios comuns, onde nos definimos em relação ao outro e à coletividade.

$\mathrm{Na}$ realidade, toda palavra comporta duas faces. Ela é determinada tanto pelo fato de que procede de alguém, como pelo fato de que se dirige para alguém. [...] Através da palavra, defino-me em relação ao outro, isto é, em última análise, em relação à coletividade. [...] A palavra é o território comum do locutor e do interlocutor. (BAKHTIN e VOLOCHÍNOV, 1981, p. 113)

Dessa forma, podemos considerar que a palavra (o discurso, o texto) é o local onde se definem identidades que são sempre relacionais. Da relação dialógica que se estabelece entre a palavra própria e a palavra alheia, dentro da perspectiva em que Bakhtin (1993) percebe as interações discursivas, surge a questão da apropriação de idéias alheias, que ocupa o centro de nossas atenções na presente pesquisa. Para Bakhtin (1993), a palavra se torna "própria" quando é povoada com a intenção do falante, com o seu acento. Até nos apropriarmos da palavra, ela é de outro(s), e não neutra - apenas no sistema abstrato da língua a palavra existe como neutra. Afinal, como nos lembra Bakhtin (1993), não é com base no dicionário que construímos nossos discursos, mas sim com base nos discursos dos outros.

Bakhtin denomina polifonia a presença de uma multiplicidade de vozes no discurso de um indivíduo. Ao referir-se à tensão que existe entre palavra própria e palavra alheia, ele irá dizer: "diversas vozes alheias lutam pela sua influência sobre a consciência do indivíduo (da mesma maneira que lutam na realidade social ambiente)" (BAKHTIN, 1993, p. 148). A polifonia caracteriza o discurso em que a dialogia se deixa ver, onde muitas vozes são percebidas. As vozes podem vir de interlocutores imediatos ou não, elas expressam teorias, tendências, visões de mundo. 
Leal, M. C.; Mortimer, E. F.

Ao tratar das transformações que a palavra alheia sofre no processo de apropriação, Bakhtin realça, novamente, a importância do aspecto contextual.

[...] o discurso de outrem incluído no contexto sempre está submetido a notáveis transformações de significado. O contexto que avoluma a palavra de outrem origina um fundo dialógico cuja influência pode ser muito grande. [...] A palavra alheia introduzida no contexto do discurso estabelece com o discurso que a enquadra não um contexto mecânico, mas uma amálgama química ${ }^{5}$ (no plano do sentido e da expressão); o grau de influência mútua do diálogo pode ser imenso. (BAKHTIN, 1993, p. 141)

Finalmente, gostaríamos de destacar a concepção de compreensão em Bakhtin. "A cada palavra da enunciação que estamos em processo de compreender, fazemos corresponder uma série de palavras nossas, formando uma réplica" (BAKHTIN e VOLOCHINOV, 1981, p. 132). A compreensão envolve, portanto, a busca de nossas próprias contrapalavras em resposta às palavras do interlocutor. Para Bakhtin (1993), qualquer compreensão verdadeira é dialógica por natureza. Desse modo, a maneira como os professores compreendem a inovação, bem como a nossa compreensão de suas compreensões devem ser tomadas em seu caráter responsivo.

Dentro da perspectiva bakhtiniana, propomos um esquema para representar a articulação de diversos discursos em torno da inovação curricular em questão, envolvendo diferentes lances de compreensão da palavra alheia e de luta entre diferentes vozes pela influência sobre os sujeitos envolvidos (Figura 2).

Percebe-se, no esquema da Figura 2, que o fluxo discursivo principal, chamemos assim, está entrelaçado com outros discursos, vindos de várias direções. Além dos quatro discursos colocados em interação no eixo vertical, há diversas vozes, tomadas no sentido de horizontes ideológico-conceituais, colocadas dos dois lados do eixo vertical central. É preciso salientar que as vozes indicadas nesse esquema não pretendem esgotar a complexidade do fenômeno em questão.

\section{O processo de coleta/produção de dados}

Para estudar a apropriação da inovação curricular, foram realizadas entrevistas semiestruturadas abordando as impressões dos professores acerca das propostas apresentadas nos cursos de formação continuada. As questões utilizadas como roteiro para o desenvolvimento das entrevistas tratavam dos seguintes temas: identificação do programa do qual o professor participou: instituição e datas; uma descrição do 'curso', as principais atividades desenvolvidas

\footnotetext{
${ }^{5}$ A analogia usada - amálgama química - não é de todo apropriada, uma vez que nas amálgamas ocorre mistura de componentes, e não reação química.
} 
Apropriação do discurso de inovação curricular ...

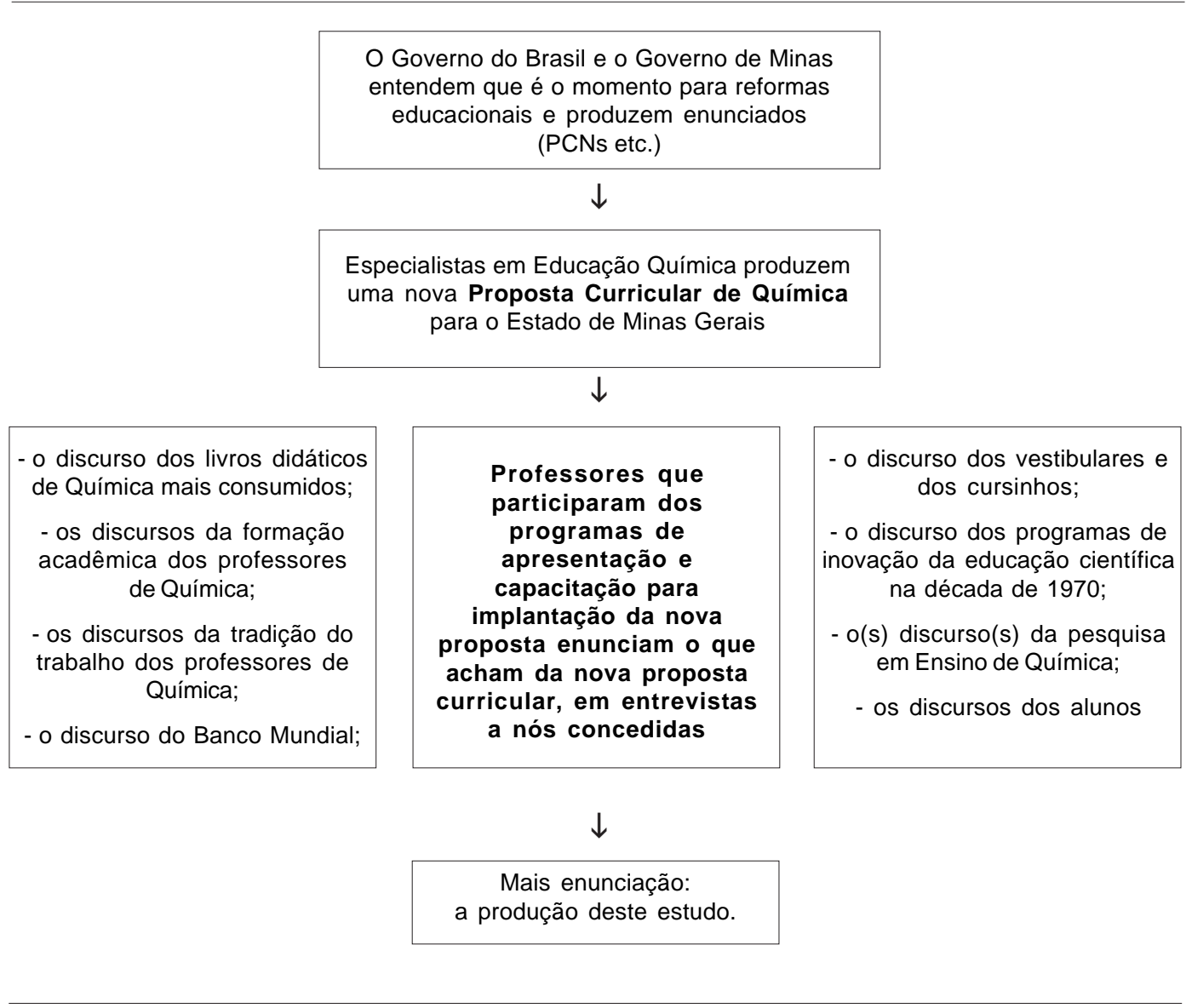

Figura 2. Representação esquemática de um conjunto de discursos e enunciações que envolvem a proposta curricular em questão.

e os materiais utilizados; do que o professor gostou mais e do que gostou menos; o que ficou do Programa na mente do professor, no seu modo de pensar e de trabalhar com o ensino da Química. Além de criarmos nomes fictícios para os professores e outras pessoas citadas, também os nomes de instituições foram omitidos. O PRÓ-MÉDIO e as diferentes edições do PRÓ-CIÊNCIAS são referidos simplesmente como Programa. A codificação utilizada nas transcrições está de acordo com as sugestões apresentadas por Marcuschi (2000) ${ }^{6}$.

\footnotetext{
${ }^{6}$ Os significados dos sinais usados são: [ ], sobreposição localizada de vozes; (+), pausas; ( ) dúvidas ou suposições; /, truncamentos bruscos; MAIÚSCULAS, ênfase ou acento forte; :::, alongamento de vogal; (( )), comentários do analista; - --, silabação; /.../, eliminação de parte da transcrição. Repetições são indicadas através de reduplicação de palavras, sílabas ou letras. Além dessa codificação, fazemos uso do sublinhado para destacar trechos que são objetos da análise.
} 
Nossa análise desdobra-se sobre fragmentos selecionados com base nos seguintes critérios: i) expressão da compreensão que os professores têm da nova proposta curricular; ii) expressão da compreensão que os professores têm de inovação curricular/educacional; iii) presença de diferentes vozes - tais como a de outros professores e a dos alunos - na estrutura discursivo-argumentativa dos professores. Além dos sujeitos sociais aos quais a palavra fora dada nos discursos dos professores ("outros professores", "alunos" etc.), instâncias institucionais (como as "licenciaturas de Química", por exemplo) e perspectivas ideológicas (tais como "empirismo" e "inovação") constituem "vozes" que nos interessam considerar e relacionar no jogo complexo da compreensão da inovação curricular em questão, com o foco na sua apropriação pelos professores do Ensino Médio.

Neste artigo, a apresentação e a discussão de resultados limitam-se a fragmentos das falas de parte dos professores entrevistados que, em nossa avaliação, permitem uma caracterização significativa das perspectivas e tensões que se destacam do conjunto geral de dados e resultados obtidos e construídos.

\section{Os professores e seus discursos}

Se inicialmente esperávamos encontrar uma reflexão centrada em retomadas nítidas dos termos do texto da nova proposta curricular, o que pudemos perceber, nas entrevistas, foi que o envolvimento e a compreensão dos professores ligaram-se às atividades desenvolvidas durante o "curso" como um todo e nas idéias mais nítidas, do ponto de vista operacional, subjacentes a tais atividades. A relação mais direta e explícita com o "texto" da nova proposta, em sentido estrito, é, efetivamente, uma ausência. Ainda que, nas entrevistas, tenhamos nos referido de modo enfático ao texto da nova proposta curricular (que foi distribuído aos professores e trabalhado durante o curso), é rara qualquer alusão mais direta a algum elemento de tal texto.

As discussões sobre conceitos e definições, bem como a proposta de uma abordagem integradora do ponto de vista dos focos de interesse da Química e dos aspectos do conbecimento químico (conforme triângulos reproduzidos anteriormente), dentre outros aspectos, estão completamente ausentes das falas dos professores. Dessa forma, percebemos, junto a eles, a construção/consolidação de uma compreensão de inovação curricular fundada na percepção do conjunto de atividades e discursos produzidos ao longo das etapas do PRÓ-MÉDIO e do PRÓ-CIÊNCIAS, nem sempre convergente com os termos da proposta veiculada por tais programas. Tal (re)construção traz consigo também as reconstruções dos professores universitários "instrutores" em tais programas, posicionados entre os autores e os destinatários do novo currículo proposto aos professores mineiros. Tais considerações já são, em si, reveladoras da complexidade dos processos de inovação curricular.

Outro aspecto importante a considerar nesse momento é a situação de entrevista. O entrevistador, professor da universidade situada na região em que atuam os professores entrevistados, já tivera contato com a maioria deles, em eventos de formação continuada e mesmo, para quatro deles, como professor na licenciatura. Essa proximidade com os entrevistados, conforme Bourdieu (1997) já argumentara, permitiu um clima amistoso e de colaboração nas entrevistas que realizamos. Por outro lado, esses professores identificavam o entrevistador 
Apropriação do discurso de inovação curricular ...

com a Universidade, um dos responsáveis pelo Programa e suas propostas; inclusive, a universidade em que o entrevistador atua participou como pólo nas edições III, IV e V do PRÓ-CIÊNCIAS. Isso pode ter gerado expectativas nos professores sobre o que responder para se conformar a essa situação de produção dos seus discursos. É impossível controlar esses aspectos ou sinalizar claramente suas influências nos discursos produzidos. De todo modo, coerentes com a perspectiva bakhtiniana de que todo discurso se dirige a alguém e está marcado pelo contexto em que é produzido, não poderíamos deixar de explicitar esses elementos das condições de produção dos discursos tomados para análise.

Finalmente, gostaríamos de salientar que, uma vez que adotamos a perspectiva bakhtiniana para a análise dos discursos dos professores, não consideramos suas diferentes enunciações como compreensões melhores ou piores da nova proposta curricular. Trata-se, na verdade, de diferentes posicionamentos em resposta ao discurso de inovação.

\section{Inovar é...}

\section{Abordar temas do dia-a-dia e realizar atividades experimentais}

Considerando o conjunto das falas dos professores, a inovação curricular é identificada especialmente com a abordagem de temas do dia-a-dia e com a realização de atividades experimentais.

A articulação do ensino da Química com materiais e processos do cotidiano é o elemento mais recorrente na percepção do que seria inovação curricular. Ela aparece com destaque na fala de dez dos 12 professores entrevistados. Essa ênfase no "dia-a-dia" (e também a ênfase em experimentação, do que trataremos logo adiante) vai ao encontro do que alguns professores já vinham pensando ou mesmo realizando, conforme seus depoimentos, em busca de um ensino de Química mais interessante. É como diz o professor Marcos: "Muita coisa que está sendo dado lá, a gente já aplicava aqui anteriormente".

$\mathrm{Na}$ maioria das vezes, essa abordagem mais contextualizada encontra um forte apoio na voz dos alunos. Tomemos, mais uma vez, um exemplo da fala do professor Marcos: "Essa maneira (a da proposta) é mais na base da contextualização. Eu achei isso muito importante, né? Porque isso torna mais atrativo pro aluno. A gente não fica tão burocrático, a Química burocrática, né?"

Em relação a esse consenso estabelecido em torno da realização de um ensino mais contextualizado, é interessante considerar o que diz Cajas (1999, p. 766): “a conexão da ciência escolar com a vida cotidiana dos estudantes é um objetivo educacional que parece simples, plausível e desejável. No entanto, este é um objeto complexo, difícil e muito pouco estudado". O autor aponta algumas fontes da dificuldade de articulação do conhecimento escolar com as temáticas do dia-a-dia: o requerimento de abordagem interdisciplinar; a ênfase, nas escolas, em sistemas idealizados bastantes simples (quando comparados aos sistemas de nossos cotidianos); a falta de formação prática/técnica dos professores, referente, por exemplo, a formulações químicas e a montagem e funcionamento de equipamentos presentes no cotidiano das pessoas. Desse modo, para articular-se ao dia-a-dia dos estudantes, a educação científica escolar deve incorporar a tecnologia, por meio de aspectos do fazer e do pensar dos engenheiros, que mais se assemelham ao que acontece na vida cotidiana. Para Campbell e 
Leal, M. C.; Mortimer, E. F.

Lubben (2000), a conexão entre ciência escolar e situações do cotidiano deve constituir um fluxo de mão dupla: o uso de experiências cotidianas para ajudar na aprendizagem do conhecimento científico e, no outro sentido, a indicação da utilidade dos conhecimentos escolares na vida dos estudantes e de suas comunidades. Santos e Mortimer (2000), por sua vez, destacam a importância de uma contextualização que envolva questões de natureza filosófica, sociológica, histórica, política e econômica. Segundo eles,

Isso se diferencia do modismo do assim chamado ensino do cotidiano, que se limita a nomear cientificamente as diferentes espécies de animais e vegetais, os produtos químicos de uso diário e os processos físicos envolvidos no funcionamento dos aparelhos eletro-eletrônicos. Um ensino que contemple apenas aspectos dessa natureza seria, a nosso ver, puramente enciclopédico, favorecendo uma cultura de almanaque. Essa seria uma forma de "dourar a pílula" [...]. (SANTOS e MORTIMER, 2000, p. 142)

Uma voz dissonante entre os entrevistados, da professora Sara, irá ressaltar que o enfoque contextualizado é mais adequado para o Ensino Fundamental. É a voz do alto nível, identificada com uma abordagem mais extensa e detalhada da "matéria", se contrapondo a abordagens que priorizam a contextualização e a interdisciplinaridade, por exemplo. Segundo Sara, é necessário centrar-se nos conteúdos químicos "pra gente ter mais tempo de trabalhar a Quimica".

Também a experimentação, a exemplo do que acontece com a contextualização no cotidiano, é recorrentemente associada à idéia de inovação no ensino de Química. No entanto, uma tensão se estabelece quando analisamos as diferentes abordagens da experimentação que surgem nas falas dos professores. Por um lado, como na fala do professor Jorge, por exemplo, a existência de um laboratório bem equipado aparece como condição necessária para um ensino de Química de qualidade. Na fala de Jorge, a falta de condições materiais aparece como fundamento de uma posição de rejeição do novo discurso curricular: "Acho que o mais importante do Programa, desses cursos, seria primeiro dar uma melhorada nas escolas, né?, prover as escolas de, sei lá, laboratório $[. .]$.

Por outro lado, a utilização de materiais alternativos, de baixo custo, na ausência de laboratórios convencionais bem equipados, aparece como uma solução viável. O professor Valter constrói em sua fala uma situação de esvaziamento da voz de resistência à inovação fundada na falta de material convencional:

"Em termos de materiais, foram usados primeiramente materiais opcionais. Eles deixaram isso bastante claro porque a nossa grande reclamação é com relação ao material que nós trabalhamos no laboratório. Então, os módulos trazem sempre material alternativo. Era a grande bronca dos professores: "não tem dinheiro pra isso, não tem pra aquilo.' Mas usa uma garrafa plástica! Aquela resistência começou a não ter mais sentido. A primeira resistência é "ah, não tem reagentes". Mas você pode comprar bicarbonato na farmácia, sulfato de cobre em loja para piscinas. Você fala "não tem béquer", você usa copo de vidro, vidro de maionese, entendeu?! Então, foi muito legal essa parte de apresentar o material alternativo. Ai porque quem quer fazer faz, com material alternativo." 
Apropriação do discurso de inovação curricular ...

No fragmento, além do próprio Valter e de um você (outros professores e também ele mesmo, como que ouvindo e falando a voz da inovação, povoando a voz da inovação com a sua própria), também aparecem eles (os proponentes, que falam a palavra da inovação) e os professores, a voz da resistência à inovação, fundada na escassez de materiais, que vai sendo esvaziada pelo argumento do uso de material alternativo.

Em outro momento da entrevista, quando perguntado sobre o que ficou do Programa em seu modo de pensar e na sua prática docente, Valter retorna à questão do uso de material alternativo. Repetidamente, ele afirma o enraizamento dessa questão em seu pensamento e em sua ação, e busca apoio a tal convicção na da voz da maioria (dos alunos e, especialmente, dos professores de química de Minas Gerais).

"Ficou com certeza. Ficou principalmente essa questão do material alternativo, essa questão está muito enraizada (Dai ele conta sobre um serviço que ele e outro professor estão organizando para fornecer e fazer manutenção de material convencional de laboratório, principalmente em escolas particulares). Eu estou mais enraizado com a parte alternativa que foi a proposta lá do Pró-Médio. Para fazer uma destilação, não tem que ter um destilador. (+) Tudo isso está muito enraizado mesmo. /.../ Essa questão ficou bastante enraizada. E essa outra questão também, não diria improvisação mas de buscar os reagentes fora das indústrias químicas, buscar nas farmácias (+) comprar o pinga-gotas, o permanganato. Valeu muito nessa parte. Isso continua comigo e com certeza com outros professores também. Com certeza isso está disseminado pela Minas Gerais inteira."

Ao destacar um aspecto da palavra inovação - o uso de material alternativo - que surge nos programas como uma tentativa de responder às precárias condições de trabalho nas escolas, Valter transforma essa palavra em algo que coincide com o seu próprio discurso. Essa é uma forma de apropriar-se do discurso de inovação que demonstra a tensão, inerente a esse processo, entre aceitação e resistência. São diversos os estudos que têm tratado da resistência dos professores à inovação ${ }^{7}$. Huberman (1976), em seu inventário de fatores que impedem a mudança em educação, destaca a desconfiança dos professores: os professores serão hostis às mudanças na escola se delas não participarem desde o início ou se as decisões forem tomadas por outros que não seus superiores hierárquicos. Mais adiante Huberman, defende a idéia de que os professores resistem, em particular, a todas as mudanças que lhes retirem autoridade sobre os alunos. Finalmente, um outro fator indicado por este autor é a ausência de processos e de formação com vistas a mudanças: os professores não contam com processos institucionalizados de divulgação de novas práticas adotadas por seus colegas, e há, igualmente, resistência à adoção de idéias de outros professores. A isso, acrescentemos a ausência de suporte, acompanhamento e avaliação sistemática da implantação e desenvolvimento de programas inovadores, como foi o caso do PRÓ-MÉDIO e do PRÓ-CIÊNCIAS, desenvolvidos em Minas Gerais de 1997 a 2001, e que constituem o cenário empírico do presente estudo.

\footnotetext{
${ }^{7}$ Destes, destacamos: Huberman (1976), Stenhouse (1991), Cronin-Jones (1991), Jenkins (1995), Black e Myron (1996), Brazão (1996), Brazão e Sanches (1997), Moreira e Borges (1997), Pena (1999), Sánchez Blanco e Valcárcel Pérez (2000), Hernández et al. (2000), Soares (2000), Silva (2001) e Neves e Borges (2001).
} 
Leal, M. C.; Mortimer, E. F.

Stenhouse (1991) considera que um juízo adverso do professor não deve ser necessariamente vinculado ao conceito de resistência; muitos dos fracassos ocorrem onde as condições são aparentemente favoráveis e onde os participantes desejam realizar a mudança. Portanto, Stenhouse prefere o conceito de "barreiras à inovação" (STENHOUSE, 1991, p. 276): falta de clareza, por parte dos participantes, a respeito de suas novas funções; falta de capacidades e conhecimentos; falta de material e equipamento; a persistência de dispositivos organizacionais incompatíveis com a inovação (como, por exemplo, o rígido horário escolar); falta de tempo; 'lacunas' que impedem a comunicação e o entendimento (por exemplo, entre o professor e os experts e entre um professor e outros professores); conflitos de valores, de poder (por conta da redistribuição de poder que as inovações podem implicar), e também conflitos práticos e psicológicos (insegurança diante do desconhecido). O autor considera que muitas dessas barreiras constituem obstáculos à aliança entre professores, administradores e pesquisadores interessados na melhoria da educação. Duas últimas considerações sobre resistência dos professores: de acordo com Sánchez Blanco e Valcárcel Pérez (2000, p. 429),

se a insatisfação inicial dos professores com sua prática docente é baixa, a predisposição e a demanda por idéias e materiais inovadores também serão baixas. Por isso, eles recomendam que as práticas comuns sejam problematizadas em situações de formação continuada, para que os professores reflitam e questionem suas concepções e práticas atuais.

Nesse sentido, cabe complementar, finalmente, com Almeida (1999, p. 255), que muitas das propostas de reforma trazem consigo o modelo do professor ideal, partindo "do pressuposto de que o professor é o único responsável pela eficácia da mudança, prescrevendo os procedimentos para que ele atinja o êxito almejado na docência"; assim, tais iniciativas/ propostas "passam ao largo das condições que permitirão aos professores reais, que estão nas escolas, tornarem-se genuínos agentes da mudança".

É interessante o modo multifacetado como o professor Valter trata a questão da experimentação no ensino da Química. Como já discutimos acima, ele realça a possibilidade e a importância de se realizarem experimentos com material alternativo. Em outro momento, ele vai contrapor experimentação ilustrativa e investigativa:

"Eu, particularmente, prefiro eu mesmo faz̧er uma demonstração, até recebo umas críticas por isso, mas eu acho mais seguro e mais proveitoso. Faço demonstração mas demonstracão investigativa, que en acho legal também; não uma demonstração assim: 'ah, vai mudar de cor, quer ver!?', não. 'Observe, mudou de cor! Por quê?' Enfim, investigativa."

Com um discurso bastante articulado, Valter vai arrolando aspectos positivos do que ele denomina "nova metodologia", identificada com a nova proposta curricular, centrado em atividades experimentais. No entanto, ao final de sua fala, quando ele fecha o balanço entre cultura escolar e inovação, o equilibrio tende para a pertinência do ensino tradicional. Entre um ensino tradicional, mais comprometido com a preparação para os exames vestibulares, e um ensino inovador, que promove um maior envolvimento e interesse dos alunos, Valter se 
Apropriação do discurso de inovação curricular ...

posiciona em favor da primeira alternativa. Seu posicionamento é condicionado pelo que diz a voz dos alunos. Focado na questão da "queda do nível", Valter diz, como se falasse a seus alunos: "[...] na hora que vocês forem cobrados, se a gente ficar aqui brincando de explodir as coisas e mudar de cor, na hora de pegar lá fora cếs vão jogar a culpa em mim: "por que ele não ensinou isso?". E diz mais: "lá no futuro quando ele precisar do conbecimento, ele vai querer ter tido aquela aula tradicional, entendeu?"

Parece, então, que a voz da inovação está dissonante tanto no espaço (cá dentro/lá fora) quanto no tempo (aqui hoje/lá no futuro). Dar a matéria e manter um nível (de quantidade e qualidade na exposição de conteúdos químicos) é o caminho mais seguro rumo a resultados importantes. Seguindo nesta direção, o discurso de Valter promove, na última parte da entrevista, uma desqualificação enfática da voz da inovação. A ela, ele vai se dirigir, várias vezes, fazendo o uso de diminutivos: "Vamos fazer uma coisinha diferente?"; "Mês que vem eu prometo fazer um negocinho"; "tradicional, dei uma mudadinha, tradicional, uma mudadinha"; "Porque senão eles pensam que tudo o que eu estou ensinando pra eles é florzinha". E diz também: "Às vezes eu também não sei trabalhar com aquela matéria de modo inovador, eu não sei mesmo, né?! Às vezes não tenho tempo de ficar correndo atrás, 'ah, como fazer essa parte diferente?’”

Nesse último fragmento, numa breve mudança de tom, Valter admite que a falta de conhecimentos e a falta de tempo interferem na incorporação de abordagens alternativas à sua prática docente.

Desde o início da fala de Valter, percebemos um reconhecimento da pertinência tanto da perspectiva inovadora quanto da tradicional. Articulá-las, achar o tamanho de cada uma dentro de sua atividade profissional, fica sendo a principal questão colocada pelo professor Valter. Como ele mesmo diz (turno 28): "eu estou com um pé no novo e tô com um pé no velho".

A importância da experimentação adquire aspectos diferenciados na fala de outros professores. Na entrevista com a professora Elisa, sempre que buscávamos informação acerca da contribuição do programa para suas concepções e prática docente, dava-se o retorno, em sua fala, à questão da reprodução em suas aulas das atividades práticas realizadas no Programa.

Elisa: "A gente pegava o material com o Cléber, o que faltava no laboratório, não tinha, a gente pegava lá com o Cléber, sabe, ia lá na Universidade procurar. Eu acho bastante válido, principalmente a parte prática, que eu gosto muito de prática, sabe. /.../"

Murilo: "Então, no seu trabalho, você considera que a influência mais forte foi essa, né, alguns experimentos."

Elisa: "É, alguns experimentos."

De acordo com Elisa, no ensino da Química, os conceitos vão aparecendo com base na realização de experimentos:

".../ ele pediu assim, que a gente não desse muito conceito pro aluno. Porque o conceito não leva a nada. Se você fizer a prática você sabe fazer a definicão, por exemplo, entendeu? Com a prática você faz o conceito. Então não é pra gente ficar só em cima do conceito não, pra gente faz̧er mais tipo assim, conte-contex-contextualização, por isso, pra deixar mais a parte de definição, conceitos, esse negócio. Que através de práticas do laboratório a gente, os alunos entenderiam a teoria, né mesmo. Que achava mais interessante essa parte. (+) Essa parte de contextua- 
Leal, M. C.; Mortimer, E. F.

lização eu lembro que ele falou muito a respeito disso e tem uma outra parte também que en (+) agora eu não me lembro mais. (++) Agora essa parte de conceito eu guardei. Inclusive eu nem dou muito conceito pros meus alunos, sabe. (Toda aula) eu explico mais uma parte assim, sabe, e eles chegam àquele conceito."

Na seqüência, a professora Elisa ilustra o seu raciocínio com o tratamento do tema "densidade":

"Eu perguntei pra eles o que é densidade, eu não falei da fórmula só. Eu lancei muita coisa assim, a respeito da densidade. Por exemplo, o densimetro, sabe, montar um densimetro pra eles, assim, pra eles aprenderem a montar o densimetro, essa parte aí, e fiz aquelas experiências da, da densidade do (+) aquela do pedacinho de madeira, aquela parte do metal que a gente coloca na água, sabe, (põe ele isolado), qual que é a densidade da água, aquele assim, sabe, qual que é maior qual que é menor. (+) Eu levei metal, pedacinhos de madeira, assim, sabe, vários tipos de madeira e mostrei pra eles, sabe, /.../ porque um pedacinho de madeira menor, ele, por exemplo, ele afunda, e o maior bóia. Esse tipo, sabe, ficar explicando pra eles pra eles chegarem a uma conclusão, entendeu?"

Murilo: "Em vez de ficar/"

Elisa: "Ficar falando de definição, com fórmulas, esse negócio, eu não trabalhei muito não. Mas assim, depois eles chegaram à conclusão e fizeram a fórmula, densidade é igual a massa sobre o volume, né. Eles chegaram a essa conclusão. EU trabalhei bastante sobre densidade com eles, sabe."

O discurso da professora Elisa pode ser visto como uma forma de apropriação da proposta (em que, de fato, muitos conceitos são discutidos com base em experimentos, nos módulos exemplares que a acompanham). Apesar de na proposta estar explicitado o papel da mediação teórica e simbólica na concepção e percepção de procedimentos experimentais, a anterioridade dos fenômenos é uma das vias de sua apropriação. Isso se reforça pelo fato de muitos professores trazerem, de sua formação inicial, a visão de Química enquanto uma ciência empírica, experimental.

Como acontece para a contextualização dos conteúdos, o apoio oferecido pela voz dos alunos é importante, também, na justificação de uma percepção positiva da realização de atividades experimentais. Vejamos um fragmento da fala da professora Flávia:

"O que en gostei mais e eu já tô até falando, né, é a respeito da parte prática mesmo. Porque a gente vê muita teoria, pega o livro e é difícil ficar passando daquele jeito, né, só do da (+) TEÓRICO. E a gente queria mesmo a parte prática. /... / eu trabalbei com uma turma de Ciências, no ano passado, o ano inteiro, e eu sempre pegava um material alternativo, levava em caixinha de sapato mesmo, punha lá na mesa, montava com eles e eles, NOSS A, se interessavam muito mais do que ficar no quadro on então falando. Eu (+) procurei fazer isso. Gostei, pela experiência que en tive aqui e pude levar pra eles."

No fragmento acima, o teórico aparece como sendo difícil e desinteressante, ao contrário do prático. A voz dos alunos, pela expressão de seu interesse e satisfação, vem apoiar essa dicotomia colocada pela professora Flávia. Temos aí, como na fala da professora Elisa, a configuração de uma oposição entre teoria e prática (experimentação) que vai na 
Apropriação do discurso de inovação curricular ...

direção oposta da integração entre os aspectos fenomenológico, teórico e representacional sugerida no texto da nova proposta.

Em trabalhos relativamente recentes, Hodson (1996, 1994, 1990) e White (1996) problematizam as finalidades normalmente atribuídas à realização de atividades experimentais nas escolas: motivação, ensino de técnicas de laboratório, intensificação da aprendizagem dos conhecimentos científicos, apresentação do "método científico", desenvolvimento de "atitudes científicas". No que se refere ao "método científico" e à aprendizagem de conhecimentos científicos, Hodson (1994) critica, de modo especial, a perspectiva indutivista que ingenuamente coloca observações experimentais como que independentes de suporte teórico precedente.

Outros temas presentes nos pressupostos da nova proposta, de cunho mais sutil ou abstrato, tais como a oposição entre procedimentos e princípios, conceitos e definições, ficaram de fora dos discursos dos professores. Isso nos leva à hipótese de que o que se faz presente nas falas dos professores não é a apropriação da nova proposta de inovação curricular, do texto que foi levado até os professores (ainda que durante as entrevistas fizéssemos alusão direta a tal texto). O que obtemos tem um sentido mais amplo, refere-se à apropriação e à reformulação do sentido de inovação curricular no ensino da Química colocado em pauta nos eventos vivenciados pelos professores.

\section{Considerações finais}

A tensão entre tradição e inovação habita, de modo diferenciado, cada um dos discursos dos 12 professores entrevistados. De acordo com os posicionamentos apresentados pelos professores, se, por um lado, contextualização e experimentação no ensino são atributos positivos, motivadores, eles podem, por outro lado, representar uma queda do nível da qualidade do ensino, percebido em função da quantidade e do detalhamento dos conteúdos químicos que são abordados ${ }^{8}$. Enquanto alguns professores destacam as más condições de trabalho, na fala de outros, a ênfase recai sobre a legitimação da abordagem conteudista, mais comprometida com o futuro dos estudantes (exames). Estes dois elementos - más condições de trabalho e a identificação com a abordagem conteudista - são os ingredientes principais da rejeição ao projeto inovador percebida junto ao grupo entrevistado.

A análise das falas dos professores deixa bastante evidente quão complexo é o processo de recontextualização de um discurso de inovação curricular produzido por especialistas. A presença das perspectivas dos estudantes - ora contra, ora a favor da inovação - e a responsabilização dos governantes em termos das precárias condições de trabalho e da falta de continuidade dos programas de formação docente imprimem um caráter menos centrado nos profes-

\footnotetext{
${ }^{8}$ Denominamos abordagem conteudista aquela caracterizada por uma exagerada ênfase na quantidade e no detalhamento dos conteúdos específicos da disciplina.
} 
Leal, M. C.; Mortimer, E. F.

sores nos desdobramentos que uma nova proposta curricular poderá produzir. A cultura escolar, apoiada pelos livros didáticos e por uma formação inicial geralmente pouco crítica, juntamente com a falta de uma proposta governamental sistemática e articulada com escolas e professores, funcionam como obstáculos poderosos ao avanço de projetos inovadores.

A recontextualização do discurso de inovação pelos professores do Ensino Médio não deve ser considerada um processo de degradação ou desgaste. Por um lado, nessa retradução orquestrada pelos saberes da experiência (como diriam TARDIF et al., 1991), o significado da inovação se amplia largamente. Do seu ponto de partida acadêmico-epistemológicopedagógico, a inovação ganha volume ao envolver diferentes demandas dos alunos e também aspectos estruturais, administrativos e operacionais, relacionados à disponibilidade de tempos e materiais, à estrutura das salas de aula, ao tamanho das turmas etc. Nesse sentido, um professor afirma: "não dá para aplicar na escola, já que as turmas são grandes e não há laboratório e material para a realização de experimentos." Por outro lado, a falta de acesso à prática da pesquisa educacional e a seus resultados, a congressos e a grupos de discussão e estudos sobre a prática educativa e os seus fundamentos, vem limitar as possibilidades da apropriação do discurso inovador realizada pelos professores do Ensino Médio.

\section{Referências}

ALMEIDA, M. I. Os professores diante das mudanças educacionais. In: BICUDO, M. A. V.; SILVA JÚNIOR, C. A. Formação do educador: organização da escola e do trabalho pedagógico. São Paulo: Editora UNESP, 1999. p. 249-261 (Seminários \& Debates, v. 3).

BAKHTIN, M. M. Os gêneros do discurso. In: Estética da criação verbal. 3 . ed. São Paulo: Martins Fontes, 2000. p. 277-326.

Questões de literatura e de estética. São Paulo: Editora Unesp, 1993.

BAKHTIN, M. M.; VOLOCHÍNOV, V. N. Marxismo e filosofia da linguagem: problemas fundamentais do método sociológico na ciência e na linguagem. 2. ed. São Paulo: Hucitec, 1981.

BARROS, D. L. P. Contribuições de Bakhtin às teorias do texto e do discurso. In: FARACO, C. A.; TEZZA, C.; CASTRO, G. (Orgs.). Diálogos com Bakhtin. Curitiba: Editora da UFPR, 1996. p. 21-42.

BLACK, P.; MYRON, A. Changing the subject: innovations in science, mathematics and thechnology education. Londres: Routledge, 1996.

BOURDIEU, P. Compreender. In: BOURDIEU, P. (Coord.) A miséria do mundo. Petrópolis: Vozes, 1997. p. 693-713.

BRASIL. Ministério da Educação e do Desporto. Fundação Coordenação de Aperfeiçoamento de Nível Superior. Relatório de atividades do Programa PRÓCIÊNCIAS - 1ª etapa. Brasília: MEC, 1999a. 
Apropriação do discurso de inovação curricular ...

Ministério da Educação e do Desporto. Parâmetros Curriculares Nacionais do Ensino Médio: Bases Legais. Brasília: MEC, 1999b.

Ministério da Educação e do Desporto. Parâmetros Curriculares Nacionais do Ensino Médio: Ciências da Natureza, Matemática e suas Tecnologias. Brasília: MEC, 1999c.

Ministério da Educação e do Desporto. Fundação Coordenação de Aperfeiçoamento de Pessoal de Nível Superior. Programa de apoio ao aperfeiçoamento de professores de $2^{\circ}$. grau em Matemática e Ciências (PRÓ-CIÊNCIAS). Brasília: MEC, 1995.

BRAZÃO, M. M. Concepções curriculares dos professores e decisões sobre o currículo formal. Revista de Educação, Lisboa, v. 6, n. 1, p. 42-62, 1996.

.; SANCHES, M. F. C. Professores e reforma curricular: práticas de inovação ou de adaptação aos contextos sistémicos da escola? Revista de Educação, Lisboa, v. VI, n. 2, p. 75-92, 1997.

CAJAS, F. Public understantding of science: using technology to enhance school science in everyday life. International Journal of Science Education, London, v. 21, n. 7, p. $765-773,1999$.

CAMPBELL, B.; LUBBEN, F. Learning science through contexts: helping pupils make sense of everyday situations. International Journal of Science Education, London, v. 22, n. 3, p. 239-252, 2000.

CRONIN-JONES, L. L. Science teacher beliefs and their influence on curriculum implementation: two case studies. Journal of Research in Science Teaching, Reston (VA, USA), v. 28, n. 3, p. 235-250, 1991.

FARACO, C. A. Bakhtin: precursor? In: MARI, H. et al. (Orgs.). Fundamentos e dimensões da análise do discurso. Belo Horizonte: Carol Borges-Núcleo de Análise do Discurso, Fale-UFMG, 1999. p. 189-199.

HERNÁNDEZ, F. et al. Aprendendo com as inovações nas escolas. Porto Alegre: Artes Médicas Sul, 2000.

HODSON, D. Practical work in school science: exploring some directions for change. International Journal of Science Education, London, v. 18, n. 7, p. 755-760, 1996.

. Hacia un enfoque más crítico del trabajo de laboratorio. Enseñanza de las Ciencias, Barcelona, v. 12, n. 3, p. 299-313, 1994.

A critical look at practical work in school science. School Science Review, Hertfordshire (England), v. 70, n. 256, p. 33-40, 1990.

HUBERMAN, A. M. Como se realizam as mudanças em educação: subsídios para o estudo do problema da inovação. São Paulo: Cultrix, 1976. 
Leal, M. C.; Mortimer, E. F.

JENKINS, E. W. Central policy and teacher response? Scientific investigations in the national curriculum of England and Wales. International Journal of Science Education, London, v. 17, n. 4, p. 471-480, 1995.

MARCUSCHI, L. A. Análise da conversação. 5. ed. São Paulo: Ática, 2000.

MINAS GERAIS. Secretaria de Estado da Educação. Programa-piloto de inovação curricular e de capacitação docente para o Ensino Médio. Proposta Curricular Química. Fundamentos teóricos e metodológicos. Belo Horizonte: SEE, 1998a.

Secretaria de Estado da Educação. Projeto-piloto de inovação curricular e de capacitação de professores do ensino médio da rede estadual de ensino de Minas Gerais. Sumário. Belo Horizonte: SEE, 1998b.

Secretaria de Estado da Educação. PROQUALIDADE. Subprojeto de melhoria do Ensino Médio. Programa-piloto de inovação curricular e capacitação docente para o Ensino Médio. Versão preliminar para discussão. Belo Horizonte: SEE, 1997.

Secretaria de Estado de Ciência e Tecnologia. Avaliação do Programa PRÓCIÊNCIAS - fase IV. Belo Horizonte: SECT, 2000a.

Secretaria de Estado de Ciência e Tecnologia. Programa PRÓ-CIÊNCIAS. PROJETO n. 04/1999. Belo Horizonte: SECT, 1999b.

Secretaria de Estado de Ciência e Tecnologia. Secretaria de Estado da Educação. Relatório de avaliação do Programa PRÓ-CIÊNCIAS III. Belo Horizonte: SECT, 1999a.

Secretaria de Estado de Ciência e Tecnologia. Secretaria de Estado da Educação. Projeto para estruturação do Programa PRÓ-CIÊNCIAS V. Belo Horizonte: SECT, 2000b.

. Secretaria de Estado de Ciência e Tecnologia. Programa PRÓ-CIÊNCIAS. Edital Concurso n. 03/1998. Belo Horizonte: SECT, 1998c.

MOREIRA, A. F.; BORGES, O. N. Estudo comparativo de reformas curriculares. In: ENCONTRO NACIONAL DE PESQUISA EM ENSINO DE CIÊNCIAS, 1., 1997, Águas de Lindóia. Anais... Águas de Lindóia: ABRAPEC, 1997. p. 36-47.

NEVES, M. L. R. C.; BORGES, O. N. Como os professores concebem os objetivos para o ensino de ciências. Revista Brasileira de Pesquisa em Educação em Ciências, v. 1, n. 3, p. 51-62, 2001.

PENA, G. A. C. A formação continuada de professoras e suas relações com a prática docente. 1999. 196 f. Dissertação (Mestrado) - Faculdade de Educação, Universidade Federal de Minas Gerais, Belo Horizonte, 1999.

SÁNCHEZ BLANCO, G.; VALCÁRCEL PÉREZ, M. V. ¿Qué tienen en cuenta los profesores cuando seleccionan el contenido de enseñanza? Cambios y dificultades tras un programa de formación. Enseñanza de las Ciencias, Barcelona, v. 18, n. 3, p. 423-437, 2000. 
Apropriação do discurso de inovação curricular ...

SANTOS, W. L. P.; MORTIMER, E. F. Uma análise de pressupostos teóricos da abordagem C-T-S (ciência-tecnologia-sociedade) no contexto da educação brasileira.

Ensaio - Pesquisa em Educação em Ciências, Belo Horizonte, v. 2, n. 2, p. 133-162, 2000 .

SILVA, P. D. S. Formação continuada e mudanças nas práticas pedagógicas: o que dizem os professores de Química. 2001. 159 f. Dissertação (Mestrado) - Faculdade de Educação, Universidade Federal de Minas Gerais, Belo Horizonte, 2001.

SOARES, C. C. Construindo a Escola Plural: a apropriação da Escola Plural por docentes do $3^{\circ}$. ciclo do Ensino Fundamental. 2000. 201 f. Dissertação (Mestrado) Faculdade de Educação, Universidade Federal de Minas Gerais, Belo Horizonte, 2000.

STENHOUSE, L. Investigación y desarrollo del curriculum. 3. ed. Madrid: Ediciones Morata,1991.

TARDIF, M. et al. Os professores face ao saber: esboço de uma problemática do saber docente. Teoria e Educação, Porto Alegre, n. 4, p. 215-233, 1991.

TODOROV, T. Prefácio. In: BAKHTIN, M. M. Estética da criação verbal. 3. ed. São Paulo: Martins Fontes, 2000. p. 1-21.

WHITE, R. T. The link between the laboratory and learning. International Journal of Science Education, London, v. 18, n. 7, p. 761-774, 1996. 